\title{
Lauren classification and individualized chemotherapy in gastric cancer (Review)
}

\author{
JUNLI MA ${ }^{1,2}$, HONG SHEN ${ }^{2,3}$, LINDA KAPESA $^{1}$ and SHAN ZENG ${ }^{1,2}$ \\ ${ }^{1}$ Department of Oncology; ${ }^{2}$ Key Laboratory for Molecular Radiation Oncology; ${ }^{3}$ Institute of Medical Sciences, \\ Xiangya Hospital, Central South University, Changsha, Hunan 410008, P.R. China
}

Received January 10, 2015; Accepted February 5, 2016

DOI: $10.3892 / \mathrm{ol} .2016 .4337$

\begin{abstract}
Gastric cancer is one of the most common malignancies worldwide. During the last 50 years, the histological classification of gastric carcinoma has been largely based on Lauren's criteria, in which gastric cancer is classified into two major histological subtypes, namely intestinal type and diffuse type adenocarcinoma. This classification was introduced in 1965, and remains currently widely accepted and employed, since it constitutes a simple and robust classification approach. The two histological subtypes of gastric cancer proposed by the Lauren classification exhibit a number of distinct clinical and molecular characteristics, including histogenesis, cell differentiation, epidemiology, etiology, carcinogenesis, biological behaviors and prognosis. Gastric cancer exhibits varied sensitivity to chemotherapy drugs and significant heterogeneity; therefore, the disease may be a target for individualized therapy. The Lauren classification may provide the basis for individualized treatment for advanced gastric cancer, which is increasingly gaining attention in the scientific field. However, few studies have investigated individualized treatment that is guided by pathological classification. The aim of the current review is to analyze the two major histological subtypes of gastric cancer, as proposed by the Lauren classification, and to discuss the implications of this for personalized chemotherapy.
\end{abstract}

\section{Contents}

1. Introduction

2. Characteristics of Lauren classification

3. Biomarkers of Lauren classification

4. Lauren classification and gastric cancer chemotherapy

5. Perspectives

Correspondence to: Professor Shan Zeng, Department of Oncology, Xiangya Hospital, Central South University, 87 Xiangya Road, Changsha, Hunan 410008, P.R. China

E-mail: zengshan2000@yeah.net

Key words: gastric cancer, Lauren classification, intestinal type, diffuse type, individualized chemotherapy

\section{Introduction}

Gastric cancer is the fourth most common type of cancer and the second leading cause of cancer-associated mortality worldwide (1). Annually 1,000,000 individuals are diagnosed with gastric cancer worldwide, resulting in 800,000 mortalities (2). The incidence of gastric cancer predominates in populations from certain geographical locations and socio-economic groups, which is considered to mainly be associated with variations in diet (1). High-incidence areas include East Asia, Eastern Europe, Central and South America, Japan and Korea, while low-incidence rates are observed in South Asia, North and East Africa, and North America (3).

Worldwide mortality rates for gastric cancer have declined in the past 10 years, however the survival rate remains low (4). Although numerous novel chemotherapy regimens have been developed for the treatment of gastric cancer, the sensitivity to treatment differs in every patient. The histological classification, in particular Lauren classification, may aid to screen patients with specific drug sensitivities.

\section{Characteristics of Lauren classification}

According to Lauren's criteria, gastric cancer is classified into two main types: Intestinal and diffuse type (5). Intestinal and diffuse gastric cancer exhibit numerous differences in pathology, epidemiology and etiology $(5,6)$.

Clinical and pathological characteristics of intestinal and diffuse gastric cancer. In intestinal tumors, tumor cells exhibit adhesion, are arranged in tubular or glandular formations and are often associated with intestinal metaplasia (5). This type of gastric cancer is associated with lymphatic or vascular invasion, and the lesions are scattered in distant positions. Intestinal gastric cancer most commonly occurs in elderly male patients, affects the gastric antrum, and exhibits a longer course and better prognosis $(6,7)$.

By contrast, in diffuse gastric cancer, tumor cells lack adhesion and infiltrate the stroma as single cells or small subgroups, leading to a population of non-cohesive, scattered tumor cells (6). Intracellular mucus may push the nucleus of the cell aside to form signet-ring cell carcinoma. The diffuse type is associated with patients of younger age and exhibits a predilection for females compared with the intestinal type (5). 
Peritoneal metastasis of diffuse gastric cancer, without easily recognized precursor lesions is common. This type of cancer usually affects the body of the stomach, and presents shorter duration and worse prognosis compared with the intestinal type $(6,8)$.

Epidemiological characteristics of intestinal and diffuse gastric cancer. Intestinal gastric cancer is more prevalent in high-risk areas, while the diffuse type is more prevalent in low-risk areas (9). In recent years, the worldwide incidence of intestinal and diffuse gastric cancer has decreased, although the decline in the diffuse type has been more gradual compared with the intestinal type, with an evident shift in histological subtype from intestinal to diffuse type adenocarcinomas (10). The tumor location in the stomach has also changed due to an increase in the incidence of gastric cardia cancer and a decrease in distal cancers (11). This trend is particularly evident in the West.

Etiology and pathogenesis of Lauren classification. The pathogenesis of intestinal and diffuse gastric carcinoma involves DNA methylation, histone modifications and chromosome recombination $(12,13)$. The two subtypes share common dietary and environmental risk factors, however, the intestinal type is more associated with environmental factors, whereas the diffuse type usually presents a genetic etiology (2).

Etiology of intestinal gastric cancer. Helicobacter pylori (HP) infection combined with diet and environmental factors is associated with the development of intestinal gastric cancer (2). The carcinogenic process involves multiple steps, including atrophic gastritis, intestinal metaplasia, dysplasia and ultimately gastric carcinogenesis (14).

$\mathrm{HP}$ is considered to be the promoter of intestinal gastric cancer, however, the hypothesis that HP eradication would prevent gastric cancer remains controversial. Previous studies $(15,16)$ have suggested that the process preceding high-level neoplasia is potentially reversible, and that the eradication of HP may decrease the probability of gastric atrophy and intestinal metaplasia, thus leading to the prevention of gastric cancer. However, certain studies have indicated that the risk of developing gastric cancer remains even once the HP infection is cured $(17,18)$. Furthermore, a previous meta-analysis revealed that curing HP infection may reduce the incidence of chronic atrophic gastritis, however, this may not prevent the development of intestinal metaplasia (19). HP eradication does not decrease the incidence of metachronous gastric carcinoma (20). Therefore, further prospective studies are required to investigate the role of HP eradication in the development of gastric cancer.

Etiology of diffuse gastric cancer. Diffuse gastric carcinoma originates from the gastric mucosa and is associated with gastritis (21). Thus, it is less affected by environmental factors than the intestinal type, although HP infection may be also involved in the development of diffuse gastric carcinoma (22). However, contrarily to intestinal gastric cancer, the diffuse type develops as a direct result of chronic active inflammation, bypassing the intermediate steps, which include atrophic gastritis and intestinal metaplasia (23). Active gastritis is considered to be a major risk factor for diffuse gastric cancer. A previous study reported that the level of DNA methylation in gastric mucosa is closely associated with HP-related gastritis, and that there may be a molecular mechanism underlying the development of diffuse gastric cancer (24).

Hereditary diffuse gastric cancer (HDGC). Of all gastric carcinomas, $\sim 80-90 \%$ are sporadic, while $10 \%$ exhibit a familial cluster; and 1-3\% patients with familial hereditary gastric cancer demonstrate particular genetic patterns (25). Familial gastric cancer includes HDGC, familial intestinal gastric cancer and familial diffuse gastric carcinoma $(26,27)$. A total of $40 \%$ of HDGC cases exhibit the characteristic E-cadherin [also known as cadherin 1, type 1 (CDH1)] gene germline mutation. To date, $>100$ germline $\mathrm{CDH} 1$ alterations have been identified, which mainly include point mutations and large deletions (28).

CDH1 mutations lead to decreased expression of CDH1, which decreases cell adhesion and activates multiple signal transduction pathways, leading to tumor invasion and metastasis. The 'two-hit theory' hypothesizes that the mutation of one allele of the CDH1 gene does not affect the expression of CDH1 (29). However, inactivation of the other allele leads to the corresponding change in protein expression (29). These two 'hits' may include methylation, somatic mutations and loss of heterozygosity. In addition, missense mutations in the tumor protein p53 and c-Met genes may also be involved in the pathogenesis of HDGC $(29,30)$.

Sporadic diffuse gastric cancer. Previous studies have demonstrated that the CDH1 mutation also occurs in sporadic diffuse gastric carcinoma (31-33). The mutation frequency is hypothesized to be $<10 \%$, however, no clear statistical data has been reported thus far (34).

Varying from the aforementioned classical two-hit model of tumor suppressor gene inactivation, $\mathrm{CDH} 1$ promoter methylation may function as the second hit in the early onset of diffuse type gastric cancer $(29,35)$. As CDH1 is currently the only unequivocal gene mutated in such patients, screening for CDH1 mutations may be recommended for suspected cases of diffuse gastric carcinoma (36).

In patients with family history of diffuse gastric carcinoma, who present the aforementioned CDH1 mutation, endoscopy should be strengthened, or preventive total gastrectomy may be recommended, as CDH1 mutation carriers have a lifetime risk of $70-80 \%$ of developing diffuse gastric cancer $(37,38)$.

\section{Biomarkers of Lauren classification}

Certain genes or proteins exhibit different levels of expression in intestinal gastric cancer, compared with diffuse gastric cancer (39-41). Thus, these genes may constitute biomarkers and may represent two different mechanisms of pathogenesis. However, the specific role of such biomarkers remains to be elucidated in order to predict the prognosis of gastric cancer.

CDH1. CDH1 mediates cell adhesion and maintains the integrity of cellular structures. Previous studies have reported that the expression of CDH1 is significantly higher in intestinal gastric cancer than in the diffuse type (42-44), which may be 
associated with the degree of differentiation. CDH1 expression is lower in less-differentiated tissues (45). Thus, CDH1 expression appears to be an early event in gastric cancer, and may serve as a useful marker for clinical prediction of gastric carcinoma.

Caudal type homeobox-2 (CDX-2). CDX-2 is important in the development of the intestinal mucosa and in maintaining cell morphology. CDX-2 does not appear in the normal gastric mucosa, but is expressed abnormally in intestinal metaplasia and intestinal gastric cancer $(46,47)$. The expression levels of CDX-2 are markedly higher in intestinal gastric cancer compared with the diffuse type $(46,47)$. A previous study indicated that CDX-2 activates the expression of the mucin 2 gene in gastric cells, inducing an intestinal trans-differentiation phenotype (48). Comparison of dysplasia and CDX-2 expression in cancer tissues has revealed that CDX-2 expression is higher in intestinal metaplasia tissues compared with the diffuse type (49), indicating that CDX-2 expression may represent an early event in gastric cancer. The majority of studies consider CDX-2 to be a positive prognostic factor (50-52).

Microsatellite instability (MSI). In total, 20\% of gastric carcinomas may be characterized by MSI, which is more common in the intestinal type compared with the diffuse type of gastric cancer (40). However, MSI is a controversial prognostic factor. Previous studies have reported that tumors with MSI exhibit a better prognosis $(40,53)$.

Other authors hypothesize that tumors with high MSI exhibit more aggressive biological behavior, leading to a poor prognosis (54). Thus, further studies on MSI, including efficacy of fluorouracil therapy, are required to guide clinical treatment.

Human epidermal growth factor receptor 2 (HER2). HER2 is a member of the HER family. Trastuzumab is used for the treatment of tumors exhibiting positive HER2 expression. Positive expression rates of HER2 in gastric cancer are reported to range from $<10$ to $30 \%$ (55). The expression of HER2 is associated with pathological tumor type. The majority of studies suggest that the HER2 positive rate is higher in the intestinal type of gastric carcinoma, compared with the diffuse type (56-58).

HER2 is involved in cellular differentiation, adhesion and apoptosis, thus being important in the development of several tumors $(59,60)$. However, the prognostic value of HER2 expression in gastric cancer remains unclear. Certain studies have indicated that gastric cancer patients with positive HER2 expression exhibit a shortened overall survival and no disease-free survival period compared with patients with negative HER2 expression $(56,61)$. However, other studies have reported that HER2 expression is not associated with disease prognosis $(57,62)$. There is little evidence regarding whether HER2 may be used as prognostic factor according to the various pathology types of gastric cancer.

In addition, a number of molecules that are differentially expressed in various gastric cancers, including tumor-associated calcium signal transducer 2, thrombospondin 4 , mothers against decapentaplegic homolog 4 and the family of transcription factors snail family zinc finger 1 , have been identified (63-66). These molecules may constitute potential biomarkers of different gastric cancer subtypes. Due to the high mortality rate and low survival rate, the identification of useful biomarkers to predict prognosis and guide clinical treatment is extremely important.

\section{Lauren classification and gastric cancer chemotherapy}

Gastric cancer is a highly heterogeneous disease, which may exhibit a variety of biological behaviors. The results of previous studies vary between the East and West and thus, it is difficult to select the optimum treatment (67). Patients exhibit different sensitivities to chemotherapy, according to Lauren classification and thus, tailoring individualized cytotoxic therapy for the treatment of gastric cancer is becoming an area of increasing interest within the scientific field (5).

Chemotherapy-associated gastric cancer genes. Chemotherapy regimens for gastric cancer have varied considerably since the 1980s. The most common chemotherapy regimens for the treatment of gastric cancer include 5-fluorouracil (5-FU), platinum, taxane, irinotecan and anthracycline. These drugs may be administered separately, using double- or triple-drug regimens in combination with epirubicin or docetaxel.

The drug-related gene, thymidylate synthetase, is the major target of 5-FU. Excision repair cross-complementing 1 and class III $\beta$-tubulin are associated with the sensitivity of cancer cells to platinum or taxane-based chemotherapy, respectively.

Detecting expression of drug-related genes prior to treatment may contribute to the selection of efficient chemotherapy drugs and to design optimal chemotherapy regimens for gastric cancer. Predicting treatment response requires comprehensive analysis of several chemotherapy-associated genes. It is also closely associated with gene polymorphisms $(68,69)$. Therefore, further studies are required to provide more information with regard to biomarker-guided individualized treatment of gastric cancer.

Chemotherapy drug efficacy according to Lauren classification. At present, no optimum combined chemotherapy regimens for advanced gastric cancer exist. The number of studies investigating drug selection according to different pathological types is limited, and the majority of these studies are observational studies, phase II clinical trials or retrospective analysis.

In the Japan Clinical Oncology Group (JCOG)9912 trial (70), no significant differences in median survival time were identified between the 5-FU, capecitabine (CAP) and $\mathrm{S}-1$ regimens. However, subgroup analysis indicated that S-1 and CAP were more efficacious than 5-FU in the treatment of diffuse gastric cancer. The First-Line Advanced Gastric Cancer Study (FLAGS) study (71) identified no significant differences between combined treatment with cisplatin and S-1, compared with 5-FU treatment alone. However, additional experiments revealed that the average survival time of patients with diffuse gastric carcinoma is longer compared with the patients with intestinal type of gastric cancer (9.0 vs. 7.1 months). The GC0301/TOP-002 clinical trial (72) compared the treatment efficacy of combined irinotecan 
and S-1 therapy with S-1 single-agent therapy for gastric cancer. The results indicated that the median survival period has reached the statistical difference only in diffuse gastric cancer. A previous phase III clinical trial (73) reported that combined therapy with irinotecan and cisplatin improved the prognosis of patients undifferentiated gastric cancer. Therefore, single-agent therapy with paclitaxel may be used in the treatment of advanced metastatic gastric cancer. Several phase II studies with small cohorts identified that diffuse gastric cancer exhibited higher effective rates compared with the intestinal type (74,75). The S-1 and Taxotere (docetaxel) therapy for Advanced gastric cancer Randomized phase III Trial (START) study (76) revealed that combined therapy with S-1 and docetaxel was superior to monotherapy with S-1 in patients with diffuse gastric cancer. These results suggest that $\mathrm{S}-1$, irinotecan and docetaxel may exhibit a certain advantage in the treatment of diffuse gastric cancer.

A number of previous studies have reported that diffuse gastric cancer is associated with peritoneal transfer, which leads to malignant ascites (5). Thus, intraperitoneal injection of paclitaxel or allied system chemotherapy (intraperitoneal injection combined with intravenous chemotherapy) represents a promising treatment option $(77,78)$. Intraperitoneal administration of the therapeutic drug, particularly for patients with peritoneal metastasis, may sustain higher intraperitoneal drug concentrations and enhance anti-tumor activity via gradual absorption through the lymphatic system. This treatment method is particularly suitable for peritoneal metastatic carcinoma. Commonly used chemotherapy regimens in Lauren classification have not been evaluated in prospective studies thus far. Further evidence-based medicine is required for individual treatment of patients under the guidance of pathological classification.

\section{Perspectives}

Gastric cancer exhibits varied sensitivity to chemotherapy drugs with strong heterogeneity. Therefore, this disease may be a candidate for individualized therapy. However, numerous problems associated with the use of individualized therapy for gastric cancer remain to be solved, including the selection of drugs for the treatment of different types of gastric carcinoma, which is mostly based on the results of previous retrospective and subgroup analyses, since no prospective studies have been conducted thus far. Due to a lack of specific molecular markers, the evidence for individualized therapy in gastric cancer is rare.

Therefore, various prospective clinical trials are required to provide the basis for individualized medicine. Treatment efficacy in gastric cancer depends on a variety of associated genes and gene polymorphisms $(55,79)$. Thus, genetic testing may identify specific predictive indicators of gastric cancer. In addition, predictive models are required to investigate individualized treatment options.

Furthermore, genotyping of gastric cancer may be more specific than pathological diagnosis. Genomic variants also have therapeutic implications, indicating a promising direction. Thus, individualized treatment may represent a potential treatment method, which would lead to significant progress in the treatment of gastric cancer in the future.

\section{Acknowledgements}

The present study was supported by the National Natural Science Foundation of China (Beijing, China; grant no's. 30770971, 81172470, 81070362 and 81372629).

\section{References}

1. Karimi P, Islami F, Anandasabapathy S, Freedman ND and Kamangar F: Gastric cancer: Descriptive epidemiology, risk factors, screening, and prevention. Cancer Epidemiol Biomarkers Prev 23: 700-713, 2014.

2. Guggenheim DE and Shah MA: Gastric cancer epidemiology and risk factors. J Surg Oncol 107: 230-236, 2013.

3. Crew KD and Neugut AI: Epidemiology of gastric cancer. World J Gastroenterol 12: 354-362, 2006.

4. Patru CL, Surlin V, Georgescu I and Patru E: Current issues in gastric cancer epidemiology. Rev Med Chir Soc Med Nat Iasi 117: 199-204, 2013.

5. Lauren P: The two histological main types of gastric carcinoma: Diffuse and so-called intestinal-type carcinoma. An attempt at a histo-clinical classification. Acta Pathol Microbiol Scand 64: 31-49, 1965.

6. Qiu MZ, Cai MY, Zhang DS, Wang ZQ, Wang DS, Li YH and $\mathrm{Xu}$ RH: Clinicopathological characteristics and prognostic analysis of Lauren classification in gastric adenocarcinoma in China. J Transl Med 11: 58, 2013.

7. Zheng H, Takahashi H, Murai Y, Cui Z, Nomoto K, Miwa S, Tsuneyama K and Takano Y: Pathobiological characteristics of intestinal and diffuse-type gastric carcinoma in Japan: An immunostaining study on the tissue microarray. J Clin Pathol 60: 273-277, 2007.

8. Chen YC, Fang WL, Wang RF, Liu CA, Yang MH, Lo SS Wu CW, Li AF, Shyr YM and Huang KH: Clinicopathological variation of lauren classification in gastric cancer. Pathol Oncol Res 22: 197-202, 2016.

9. Hommel C, Knoedler M, Bojarski C, Schumann M, Epple HJ, Zeitz $M$ and Daum S: Diffuse gastric cancer with peritoneal carcinomatosis can mimic Crohn's disease. Case Rep Gastroenterol 6: 695-703, 2012.

10. Stiekema J, Cats A, Kuijpers A, van Coevorden F, Boot H, Jansen EP, Verheij M, Balague Ponz O, Hauptmann M and van Sandick JW: Surgical treatment results of intestinal and diffuse type gastric cancer. Implications for a differentiated therapeutic approach? Eur J Surg Oncol 39: 686-693, 2013.

11. Kaneko S and Yoshimura T: Time trend analysis of gastric cancer incidence in Japan by histological types, 1975-1989. Br J Cancer 84: 400-405, 2001.

12. Yamamoto E, Suzuki H, Takamaru H, Yamamoto H, Toyota M and Shinomura Y: Role of DNA methylation in the development of diffuse-type gastric cancer. Digestion 83: 241-249, 2011.

13. Fu DG: Epigenetic alterations in gastric cancer. Mol Med Rep 12: 3223-3230, 2015 (Review).

14. Martínez-Madrigal F, Ortiz-Hidalgo C, Torres-Vega C, Alvarez L, Manzo-Montaño A, García-López L and Esquivel-Ayanegui F: Atypical regenerative changes, dysplasia, and carcinoma in situ in chronic gastritis associated with Helicobacter pylori. Rev Gastroenterol Mex 65: 11-17, 2000 (In Spanish).

15. Kodama M, Murakami K, Okimoto T, Abe T, Nakagawa Y, Mizukami K, Uchida M, Inoue $\mathrm{K}$ and Fujioka T: Helicobacter pylori eradication improves gastric atrophy and intestinal metaplasia in long-term observation. Digestion 85: 126-130, 2012.

16. Asaka M: Elimination of gastric cancer from Japan. Nihon Rinsho 70: 1667-1672, 2012 (In Japanese).

17. Take S, Mizuno M, Ishiki K, Yoshida T, Ohara N, Yokota K, Oguma K, Okada H and Yamamoto K: The long-term risk of gastric cancer after the successful eradication of Helicobacter pylori. J Gastroenterol 46: 318-324, 2011.

18. Vannella L, Lahner E and Annibale B: Risk for gastric neoplasias in patients with chronic atrophic gastritis: A critical reappraisal. World J Gastroenterol 18: 1279-1285, 2012.

19. Rokkas T, Pistiolas D, Sechopoulos P, Robotis I and Margantinis G: The long-term impact of Helicobacter pylori eradication on gastric histology: A systematic review and meta-analysis. Helicobacter 12 (Suppl 2): S32-S38, 2007. 
20. Maehata Y, Nakamura S, Fujisawa K, Esaki M, Moriyama T, Asano K, Fuyuno Y, Yamaguchi K, Egashira I, Kim H, et al: Long-term effect of Helicobacter pylori eradication on the development of metachronous gastric cancer after endoscopic resection of early gastric cancer. Gastrointest Endosc 75: 39-46, 2012.

21. Pereyra L, Gómez EJ, Mella JM, Casas G, Bugari G, Cimmino D, Pedreira S and Boerr LA: Diffuse gastric cancer associated with Ménétrier's disease. Acta Gastroenterol Latinoam 41: 142-145, 2011 (In Spanish).

22. Palestro G, Pellicano R, Fronda GR, Valente G, De Giuli M, Soldati T, Pugliese A, Taraglio S, Garino M, Campra D, et al: Prevalence of Helicobacter pylori infection and intestinal metaplasia in subjects who had undergone surgery for gastric adenocarcinoma in Northwest Italy. World J Gastroenterol 11: 7131-7135, 2005

23. Nardone G, Rocco A and Malfertheiner P: Review article: Helicobacter pylori and molecular events in precancerous gastric lesions. Aliment Pharmacol Ther 20: 261-270, 2004

24. Yoshida T, Kato J, Maekita T, Yamashita S, Enomoto S, Ando T, Niwa T, Deguchi H, Ueda K, Inoue I, et al: Altered mucosal DNA methylation in parallel with highly active Helicobacter pylori-related gastritis. Gastric Cancer 16: 488-497, 2013

25. Corso G, Marrelli D and Roviello F: Familial gastric cancer: Update for practice management. Fam Cancer 10: 391-396, 2011.

26. Oliveira C, Pinheiro H, Figueiredo J, Seruca R and Carneiro F. Familial gastric cancer: Genetic susceptibility, pathology, and implications for management. Lancet Oncol 16: e60-e70, 2015

27. Vogelaar IP, van der Post RS, Bisseling TM, van Krieken JH, Ligtenberg MJ and Hoogerbrugge N: Familial gastric cancer: Detection of a hereditary cause helps to understand its etiology. Hered Cancer Clin Pract 10: 18, 2012.

28. Carneiro F: Hereditary gastric cancer. Pathologe 33 (Suppl 2): S231-S234, 2012.

29. Machado JC, Oliveira C, Carvalho R, Soares P, Berx G, Caldas C, Seruca R, Carneiro F and Sobrinho-Simöes M: E-cadherin gene $(\mathrm{CDH} 1)$ promoter methylation as the second hit in sporadic diffuse gastric carcinoma. Oncogene 20: 1525-1528, 2001.

30. Kim IJ, Kang HC, Shin Y, Park HW, Jang SG, Han SY, Lim SK, Lee MR, Chang HJ, Ku JL, et al: A TP53-truncating germline mutation $(\mathrm{E} 287 \mathrm{X})$ in a family with characteristics of both hereditary diffuse gastric cancer and Li-Fraumeni syndrome. J Hum Genet 49: 591-595, 2004.

31. Kim S, Chung JW, Jeong TD, Park YS, Lee JH, Ahn JY, Kim DH, Choi KD, Lee W, Song HJ, et al: Searching for E-cadherin gene mutations in early onset diffuse gastric cancer and hereditary diffuse gastric cancer in Korean patients. Fam Cancer 12: 503-507, 2013.

32. Bacani JT, Soares M, Zwingerman R, di Nicola N, Senz J, Riddell R, Huntsman DG and Gallinger S: CDH1/E-cadherin germline mutations in early-onset gastric cancer. J Med Genet 43 : 867-872, 2006

33. Corso G, Pedrazzani C, Pinheiro H, Fernandes E, Marrelli D, Rinnovati A, Pascale V, Seruca R, Oliveira C and Roviello F: E-cadherin genetic screening and clinico-pathologic characteristics of early onset gastric cancer. Eur J Cancer 47: 631-639, 2011.

34. Humar B, Graziano F, Cascinu S, Catalano V, Ruzzo AM Magnani M, Toro T, Burchill T, Futschik ME, Merriman T and Guilford P: Association of CDH1 haplotypes with susceptibility to sporadic diffuse gastric cancer. Oncogene 21: 8192-8195, 2002

35. Liu YC, Shen CY, Wu HS, Hsieh TY, Chan DC, Chen CJ, Yu JC, Yu CP, Harn HJ, Chen PJ, et al: Mechanisms inactivating the gene for E-cadherin in sporadic gastric carcinomas. World J Gastroenterol 12: 2168-2173, 2006

36. Ramos-de la Medina A, More H, Medina-Franco H, Humar B Gamboa A, Ortiz LJ, Donohue JH and Guilford P: Single nucleotide polymorphisms (SNPs) at $\mathrm{CDH} 1$ promoter region in familial gastric cancer. Rev Esp Enferm Dig 98: 36-41, 2006.

37. Hoogerbrugge N, Ligtenberg MJ, Nagengast FM, Bonenkamp JJ and van Krieken JH: Preventive resection of hereditary diffuse gastric cancer. Ned Tijdschr Geneeskd 150: 2417-2420, 2006 (In Dutch).

38. Kluijt I, Sijmons RH, Hoogerbrugge N, Vasen HF and Cats A: Familial gastric cancer: Diagnosis, treatment and periodic surveillance. Ned Tijdschr Geneeskd 155: A2731, 2011 (In Dutch).
39. Schildberg CW, Abba M, Merkel S, Agaimy A, Dimmler A Schlabrakowski A, Croner R, Leupold JH, Hohenberger W and Allgayer H: Gastric cancer patients less than 50 years of age exhibit significant downregulation of E-cadherin and CDX2 compared to older reference populations. Adv Med Sci 59: 142-146, 2014.

40. Kim H, An JY, Noh SH, Shin SK, Lee YC and Kim H: High microsatellite instability predicts good prognosis in intestinal-type gastric cancers. J Gastroenterol Hepatol 26: 585-592, 2011 .

41. Qiu M, Zhou Y, Zhang X, Wang Z, Wang F, Shao J, Lu J, Jin Y, Wei X, Zhang D, et al: Lauren classification combined with HER2 status is a better prognostic factor in Chinese gastric cancer patients. BMC Cancer 14: 823, 2014

42. Wu ZY, Zhan WH, Li JH, He YL, Wang JP, Lan P, Peng JS and Cai SR: Expression of E-cadherin in gastric carcinoma and its correlation with lymph node micrometastasis. World J Gastroenterol 11: 3139-3143, 2005.

43. Lazăr D, Tăban S, Ardeleanu C, Dema A, Sporea I, Cornianu M, Lazăr E and Vernic C: The immunohistochemical expression of E-cadherin in gastric cancer; correlations with clinicopathological factors and patients' survival. Rom J Morphol Embryol 49: 459-467, 2008.

44. Stănculescu D, Mărgăritescu C, Stepan A and Mitruţ AO: E-cadherin in gastric carcinomas related to histological prognostic parameters. Rom J Morphol Embryol 52 (Suppl 3): S1107-S1112, 2011.

45. Karayiannakis AJ, Syrigos KN, Chatzigianni E, Papanikolaou S and Karatzas G: E-cadherin expression as a differentiation marker in gastric cancer. Hepatogastroenterology 45: 2437-2442, 1998.

46. Asano N, Imatani A, Watanabe T, Fushiya J, Kondo Y, Jin X, Ara N, Uno K, Iijima K, Koike T, et al: Cdx2 expression and intestinal metaplasia induced by $H$. pylori infection of gastric cells is regulated by NOD1-mediated innate immune responses. Cancer Res: Jan 12, 2016 (Epub ahead of print).

47. Almeida R, Almeida J, Shoshkes M, Mendes N, Mesquita P, Silva E, Van Seuningen I, Reis CA, Santos-Silva F and David L: OCT-1 is over-expressed in intestinal metaplasia and intestinal gastric carcinomas and binds to, but does not transactivate, CDX2 in gastric cells. J Pathol 207: 396-401, 2005.

48. Mesquita P, Jonckheere N, Almeida R, Ducourouble MP, Serpa J, Silva E, Pigny P, Silva FS, Reis C, Silberg D, et al: Human MUC2 mucin gene is transcriptionally regulated by $\mathrm{Cdx}$ homeodomain proteins in gastrointestinal carcinoma cell lines. J Biol Chem 278: 51549-51556, 2003.

49. Kim HS, Lee JS, Freund JN, Min KW, Lee JS, Kim W, Juhng SW and Park CS: CDX-2 homeobox gene expression in human gastric carcinoma and precursor lesions. J Gastroenterol Hepatol 21: 438-442, 2006.

50. Seno H, Oshima M, Taniguchi MA, Usami K, Ishikawa TO, Chiba T and Taketo MM: CDX2 expression in the stomach with intestinal metaplasia and intestinal-type cancer: Prognostic implications. Int J Oncol 21: 769-774, 2002.

51. Mizoshita T, Tsukamoto T, Nakanishi H, Inada K, Ogasawara N, Joh T, Itoh M, Yamamura Y and Tatematsu M: Expression of Cdx2 and the phenotype of advanced gastric cancers: Relationship with prognosis. J Cancer Res Clin Oncol 129: 727-734, 2003

52. Fan Z, Li J, Dong B and Huang X: Expression of Cdx 2 and hepatocyte antigen in gastric carcinoma: Correlation with histologic type and implications for prognosis. Clin Cancer Res 11: 6162-6170, 2005

53. Fang WL, Chang SC, Lan YT, Huang KH, Chen JH, Lo SS, Hsieh MC, Li AF, Wu CW and Chiou SH: Microsatellite instability is associated with a better prognosis for gastric cancer patients after curative surgery. World J Surg 36: 2131-2138, 2012.

54. Kim JY, Shin NR, Kim A, Lee HJ, Park WY, Kim JY, Lee CH, Huh GY and Park DY: Microsatellite instability status in gastric cancer: A reappraisal of its clinical significance and relationship with mucin phenotypes. Korean J Pathol 47: 28-35, 2013.

55. Yuan DD, Zhu ZX, Zhang X and Liu J: Targeted therapy for gastric cancer: Current status and future directions. Oncol Rep 35: 1245-1254, 2016 (Review).

56. Park DI, Yun JW, Park JH, Oh SJ, Kim HJ, Cho YK, Sohn CI, Jeon WK, Kim BI, Yoo CH, et al: HER-2/neu amplification is an independent prognostic factor in gastric cancer. Dig Dis Sci 51: 1371-1379, 2006 
57. Janjigian YY, Werner D, Pauligk C, Steinmetz K, Kelsen DP Jäger E, Altmannsberger HM, Robinson E, Tafe LJ, Tang LH, et al: Prognosis of metastatic gastric and gastroesophageal junction cancer by HER2 status: A European and USA International collaborative analysis. Ann Oncol 23: 2656-2662, 2012

58. Sornmayura P, Rerkamnuaychoke B, Jinawath A and Euanorasetr C: Human epidermal growth-factor receptor 2 overexpression in gastric carcinoma in Thai patients. J Med Assoc Thai 95: 88-95, 2012.

59. Ishida M, Kagawa S, Shimoyama K, Takehara K, Noma K, Tanabe S, Shirakawa Y, Tazawa H, Kobayashi H and Fujiwara T: Trastuzumab-based photoimmunotherapy integrated with viral HER 2 transduction inhibits peritoneally disseminated HER2-negative cancer. Mol Cancer Ther: Feb 1, 2016 (Epub ahead of print).

60. Gagliato DM, Jardim DL, Marchesi MS and Hortobagyi GN: Mechanisms of resistance and sensitivity to anti-HER2 therapies in HER2+ breast cancer. Oncotarget, 2016.

61. Liu W, Zhong S, Chen J and Yu Y: HER-2/neu overexpression is an independent prognostic factor for intestinal-type and early-stage gastric cancer patients. J Clin Gastroenterol 46: e31-e37, 2012.

62. Wu HM, Liu YH, Lin F, Xu FP, Luo DL, Zhang F, Zhuang HG, Luo XL, Wu WL and Lin XT: Association of HER2 protein expression with clinicopathologic features and prognosis in Chinese patients with gastric carcinoma. Zhonghua Bing Li Xue Za Zhi 40: 296-299, 2011 (In Chinese).

63. Förster S, Gretschel S, Jöns T, Yashiro M and Kemmner W: THBS4, a novel stromal molecule of diffuse-type gastric adenocarcinomas, identified by transcriptome-wide expression profiling. Mod Pathol 24: 1390-1403, 2011.

64. Kim MA, Lee HS, Yang HK and Kim WH: Clinicopathologic and protein expression differences between cardia carcinoma and noncardia carcinoma of the stomach. Cancer 103: 1439-1446, 2005

65. Zhao W, Zhu H, Zhang S, Yong H, Wang W, Zhou Y, Wang B, Wen J, Qiu Z, Ding G, et al: Trop2 is overexpressed in gastric cancer and predicts poor prognosis. Oncotarget: Dec 22, 2015 (Epub ahead of print)

66. He HY, Wang XF, Shen ZB, Chen WD and Sun YH: Association of transcriptional repressor Snail with Lauren classification of gastric cancer. Zhonghua Wei Chang Wai Ke Za Zhi 15: 852-854, 2012 (In Chinese).

67. Jackson C, Mochlinski K and Cunningham D: Therapeutic options in gastric cancer: neoadjuvant chemotherapy vs postoperative chemoradiotherapy. Oncology (Williston Park) 21: 1084-1087, 1090, 1096-1098, 1101, 2007.

68. Park SR, Kong SY, Nam BH, Choi IJ, Kim CG, Lee JY, Cho SJ, Kim YW, Ryu KW, Lee JH, et al: CYP2A6 and ERCC1 polymorphisms correlate with efficacy of S-1 plus cisplatin in metastatic gastric cancer patients. Br J Cancer 104: 1126-1134, 2011.

69. Wang Z, Chen JQ, Liu JL, Qin XG and Huang Y: Polymorphisms in ERCC1, GSTs, TS and MTHFR predict clinical outcomes of gastric cancer patients treated with platinum/5-Fu-based chemotherapy: A systematic review. BMC Gastroenterol 12: 137, 2012.
70. Takahari D, Boku N, Mizusawa J, Takashima A, Yamada Y, Yoshino T, Yamazaki K, Koizumi W, Fukase K, Yamaguchi K, et al: Determination of prognostic factors in Japanese patients with advanced gastric cancer using the data from a randomized controlled trial, Japan clinical oncology group 9912. Oncologist 19: 358-366, 2014.

71. Ajani JA, Rodriguez W, Bodoky G, Moiseyenko V, Lichinitser M, Gorbunova V, Vynnychenko I, Garin A, Lang I and Falcon S: Multicenter phase III comparison of cisplatin/S-1 with cisplatin/infusional fluorouracil in advanced gastric or gastroesophageal adenocarcinoma study: The FLAGS trial. J Clin Oncol 28: 1547-1553, 2010.

72. Narahara H, Iishi H, Imamura $H$, Tsuburaya A, Chin $K$, Imamoto H, Esaki T, Furukawa H, Hamada C and Sakata Y: Randomized phase III study comparing the efficacy and safety of irinotecan plus S-1 with S-1 alone as first-line treatment for advanced gastric cancer (study GC0301/TOP-002). Gastric Cancer 14: 72-80, 2011.

73. Boku N, Yamamoto S, Fukuda H, Shirao K, Doi T, Sawaki A, Koizumi W, Saito H, Yamaguchi K, Takiuchi $\mathrm{H}$, et al; Gastrointestinal Oncology Study Group of the Japan Clinical Oncology Group: Fluorouracil versus combination of irinotecan plus cisplatin versus S-1 in metastatic gastric cancer: A randomised phase 3 study. Lancet Oncol 10: 1063-1069, 2009.

74. Yamaguchi K, Tada M, Horikoshi N, Otani T, Takiuchi H, Saitoh S, Kanamaru R, Kasai Y, Koizumi W, Sakata Y and Taguchi T; Paclitaxel Gastric Cancer Study Group in Japan: Phase II study of paclitaxel with 3-h infusion in patients with advanced gastric cancer. Gastric Cancer 5: 90-95, 2002.

75. Kato K, Chin K, Yoshikawa T, Yamaguchi K, Tsuji Y, Esaki T, Sakai K, Kimura M, Hamaguchi T, Shimada Y, et al: Phase II study of NK105, a paclitaxel-incorporating micellar nanoparticle, for previously treated advanced or recurrent gastric cancer. Invest New Drugs 30: 1621-1627, 2012.

76. Koizumi W, Kim YH, Fujii M, Kim HK, Imamura H, Lee KH, Hara T, Chung HC, Satoh T, Cho JY, et al; JACCRO and KCSG Study Group: Addition of docetaxel to S-1 without platinum prolongs survival of patients with advanced gastric cancer: A randomized study (START). J Cancer Res Clin Oncol 140: 319-328, 2014.

77. Kobayashi M, Sakamoto J, Namikawa T, Okamoto K, Okabayashi T, Ichikawa K and Araki K: Pharmacokinetic study of paclitaxel in malignant ascites from advanced gastric cancer patients. World J Gastroenterol 12: 1412-1415, 2006.

78. Kitayama J, Ishigami H, Yamaguchi H, Yamashita H, Emoto S and Kaisaki S: S-1 plus intravenous and intraperitoneal Paclitaxel for gastric cancer with peritoneal metastasis. Gastrointest Cancer Res 5 (Suppl 1): S10-S13, 2012.

79. Toriumi F, Kubota T, Saikawa Y, Yoshida M, Otani Y, Watanabe M, Kumai K and Kitajima M: Thymidylate synthetase (TS) genotype and TS/dihydropyrimidine dehydrogenase mRNA level as an indicator in determining chemosensitivity to 5-fluorouracil in advanced gastric carcinoma. Anticancer Res 24: 2455-2463, 2004. 